\title{
DISTANCE EDUCATION: GETTING FURTHER
}

\author{
Isabel Amélia Costa Mendes ${ }^{1}$ \\ Maria Helena Palucci Marziale ${ }^{2}$
}

The global movement around the Millennium Goals has been translated by the union of governments and the convergence of strategies able to achieve them. Monitoring demonstrates stimulating results of the education for all policy, based on human rights and on the importance of learning across the life cycle. In the health area, WHO declared 2006-2015 as the Decade of Human Resources in Health, in order to signal and involve governments and companies in a clear policy to value people active in this kind of services.

It is in this context that in each country, sector, career and organization, strategies in the light of a global policy are being reproduced and improved.

Among the possible strategies, Distance Education has been increasingly selected and adopted. For the sake of illustration, the year 2007 offered good opportunities for institutions, professionals, researchers and students to participate in events about themes related to distance education and telehealth. In this sense, the following events stand out: Contic-Health 2007, held by the Ribeirão Preto College of Nursing; the III Brazilian Telemedicine Congress, held by the Brazilian Council of Telemedicine and Telehealth, the International E-learning Congress Brazil 2007 by the E-Learning Portal Brazil and the $13^{\text {th }}$ International Distance Education Congress, promoted by ABED - Brazilian Association of Distance Education.

During these meetings, various aspects related to e-learning were presented and discussed, such as the influence of leadership in Distance Education institutions and the application of technology to education with a view to quality improvement. Another source of important discussion was the focus on comprehensive education.

The main themes addressed include: use of e-learning in the continuous improvement of individual and organizational performance; how individual and organizational performance actually contribute to achieve expected results; and how to get to know the state of the art in technology use to support teaching/learning processes.

There seems to be a consensus on the need to invest in education, although questions remain about its dimension and range. Injecting large amounts of financial resources does not necessarily imply successful Distance Education projects in practice. Other factors, such as quality concern, team training and the creation of an institutional culture, are fundamental for the success of a program or project.

In this context, doubts also emerge about the appropriateness of applying foreign virtual education models to a country that is still marked by a series of inequalities, a large universe of digitally excluded people and conventional education. On the other hand, attending as many students as possible should not be the only focus. Instead, efforts should focus on sustainable quality, that is, high-quality Distance Education programs at costs that are coherent with Brazilian institutions' investment conditions.

To reach the quality targets, it is important for institutions focused on education to be connected also with large and globally renowned associations, such as the International Council for Open and Distance Education - ICDE and the Sloan Consortium (Sloan-C), and for this movement to permit the creation of new networks for sharing experiences and adopting standards.

The global scenario also reveals new open-access scientific journals specialized in distance education. One example is The International Review of Research in Open and Distance Learning, issued by Athabasca University - Canada's Open University. Moreover, teaching institutions are strengthened through complete virtual programs at technical, undergraduate and graduate level.

In the Nursing area, the University of Wisconsin - Madison, USA stands out as an example of online programs. For ten years, this institution has been offering the Collaborative Nursing Program (CNP) through the Distance Education platform WebCt.

Editors of Latin American Journal of Nursing of Ribeirão Preto of the University of São Paulo at Ribeirão Preto College of Nursing - WHO Collaborating Centre for Nursing Research Development, Brazil: ${ }^{1}$ Full Professor, e-mail: iamendes@eerp.usp.br; ${ }^{2}$ Full Professor, e-mail: marziale@eerp.usp.br 
Other examples of online universities are the American Inter Continental University, which offers courses in business administration, education and health care, among others. The Colorado Technical University Online is already offering fully online courses at Bachelor and Master's level, even for students outside the American or Canadian territory, where its headquarters are located. These institutions are part of "The World's Premier Online Directory of Education", created in 1999 and headquartered in Alberta, Canada.

In Brazil, there are clear signs of evolution in Distance Education through the strengthening of national associations, such as the Brazilian Association of Distance Education, and through the creation of the Distance Education Secretary, which is affiliated with the Ministry of Education. The Open University, created by the federal government, has already started its activities in 2006, offering a pilot course with 10,000 places, and planning to expand the number of courses and revising Distance Education legislation in 2008.

In short, these examples demonstrate one of the strategies used by professionals and institutions that have embraced the policy of valuing people and have incorporated the view that any mobilization is valid to exercise the duty and right of all to receive permanent education. 